\title{
Analysis of Multiconductor Coupled-Line Marchand Baluns for Miniature MMIC Design
}

\author{
Chin-Shen Lin, Student Member, IEEE, Pei-Si Wu, Student Member, IEEE, Mei-Chao Yeh, \\ Jia-Shiang Fu, Student Member, IEEE, Hong-Yeh Chang, Member, IEEE, Kun-You Lin, Member, IEEE, and \\ Huei Wang, Fellow, IEEE
}

\begin{abstract}
The analysis and systematic design procedure for multiconductor coupled-line Marchand baluns are presented in this paper. A simple two-conductor coupled-line model is used to analyze the Marchand balun and simplify the analysis significantly. Two monolithic balanced frequency doublers with miniature Marchand baluns are implemented to verify the design procedure. Both the chips achieve the smallest chip sizes at their operating frequencies with comparable performance.
\end{abstract}

Index Terms-Balun, diode, frequency doubler, Marchand balun, monolithic microwave integrated circuit (MMIC).

\section{INTRODUCTION}

B ALUNS ARE important components for many microwave and millimeter-wave circuits such as balanced mixers, frequency doublers, and balanced amplifiers. There are various balun configurations reported for monolithic microwave integrated circuit (MMIC) applications. Marchand baluns have broadband performance and can be easily implemented on planar structures and, therefore, are suitable for MMIC design. The planar Marchand baluns, which are composed of two coupled-line sections, have been realized by using multilayer coupled structure [1], two-conductor edge-coupled lines [2], three-conductor edge-coupled lines [3], multiconductor edge-coupled lines (i.e., Lange couplers) [4], and spiral-shaped coupled lines [5].

In order to broaden the bandwidth of the Marchand balun, the coupled-line sections with a high coupling coefficient are desired. Multiconductor coupled lines were often used to achieve a high coupling coefficient in the planar structure. The bandwidth analysis for three-conductor coupled-line Marchand baluns has

Manuscript received October 17, 2006; revised February 5, 2007. This work was supported in part by the National Science Council of Taiwan, R.O.C., under Grant NSC 95-2752-E-002-003-PAE, Grant NSC 95-2219-E-002-009, and Grant NSC 95-2218-E-002-057, and by National Taiwan University under the Excellent Research Project 95R0062-AE00-00.

C.-S. Lin, K.-Y. Lin, and H. Wang are with the Department of Electrical Engineering and Graduate Institute of Communication Engineering, National Taiwan University, Taipei 10617, Taiwan, R.O.C. (e-mail: hueiwang@ew.ee. ntu.edu.tw; kunyou@ntu.edu.tw).

P.-S. Wu and M.-C. Yeh were with the Graduate Institute of Communication Engineering, National Taiwan University, Taipei 10617, Taiwan, R.O.C. They are now with the Realtek Semiconductor Corporation, Hsinchu 300, Taiwan, R.O.C..

J.-S. Fu was with the Department of Electrical Engineering and Computer Science, National Taiwan University, Taipei 10617, Taiwan, R.O.C. He is now with the The University of Michigan at Ann Arbor, Ann Arbor, MI 48109 USA.

H.-Y. Chang is with the Department of Electrical Engineering, National Central University, Jhongli City, Taoyuan County 32001, Taiwan, R.O.C.

Digital Object Identifier 10.1109/TMTT.2007.897689 been reported [6], but there is lack of analysis for multiconductor coupled-line Marchand baluns.

The multiconductor coupled-line Marchand baluns are usually designed using circuit simulators. However, it is not easy to tune the multiple parameters of the balun to achieve desired performance. A computer-aided analysis and design procedure for a planar multilayer Marchand balun was reported in [1] with complex design equations, but there is no systematic design procedure to design multiconductor coupled-line Marchand baluns.

In this paper, the relation between the Marchand balun bandwidth and two-conductor-coupled-line coupling coefficient is investigated. We also demonstrate that the multiconductor coupled lines can be simplified as a pair of equivalent two-conductor coupled lines. The equivalent two-conductor coupled lines are generally asymmetrical coupled lines and can be analyzed with $c$ and $\pi$ modes [9]. By assuming the phase velocities of the $c$ and $\pi$ modes to be the same, the impedances of the equivalent two-conductor coupled line can be extracted to calculate the coupling coefficient. A systematic design procedure for the multiconductor coupled-line Marchand balun is then proposed, and the design parameters can be determined easily. Using this design procedure, two MMIC balanced frequency doublers are demonstrated and achieve small chip sizes with comparable performance.

\section{Analysis And Design Procedure of Multiconductor COUPLED-LINE MARCHAND BALUNS}

\section{A. Marchand Balun Analysis}

If the termination impedances of an asymmetrical coupled line are chosen to be equal to the characteristic impedances of the individual uncoupled lines, the propagation constant of the $c$ and $\pi$ modes are assumed to be equal. This assumption will be examined later. The four-port $S$-parameters of the asymmetric two-conductor coupled lines, which has the electrical length of $\theta$, is given by

$$
[S]_{\text {coupler }}=\left[\begin{array}{cccc}
0 & x / z & y / z & 0 \\
x / z & 0 & 0 & y / z \\
y / z & 0 & 0 & x / z \\
0 & y / z & x / z & 0
\end{array}\right]
$$

where $x=\sqrt{1-k^{2}}, y=j k \sin \theta$, and $z=\sqrt{1-k^{2}} \cos \theta+$ $j \sin \theta$, and $k$ is the coupling coefficient [8].

The block diagram of a Marchand balun, which consists of two identical coupled-line sections, is shown in Fig. 1 [7]. The termination impedances of port $1-3$ are $Z_{1}, Z_{2}$, and $Z_{2}$, which 


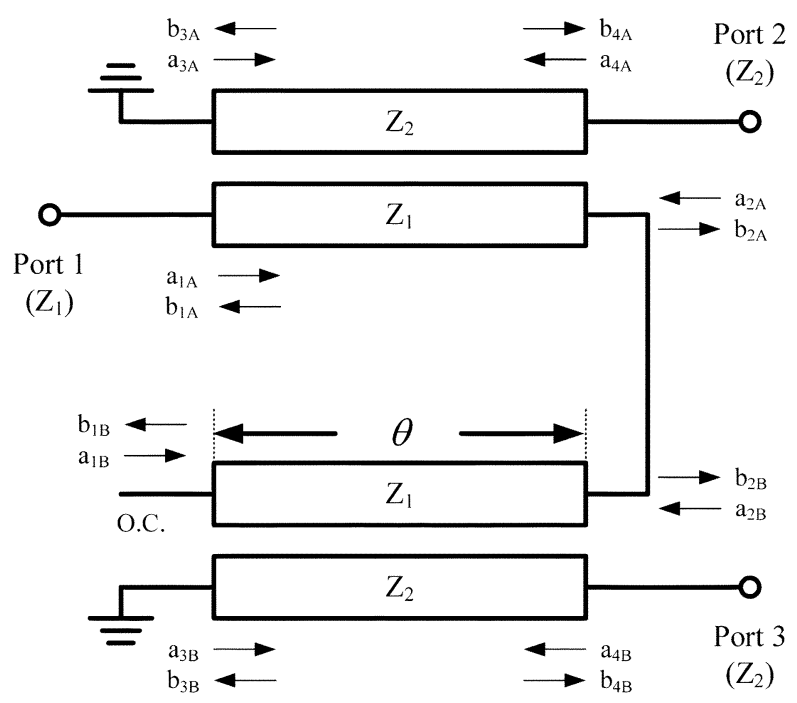

Fig. 1. Block diagram of a Marchand balun with two identical coupled-line sections. The characteristic impedances of the individual uncoupled lines in the coupled-line section are $Z_{1}$ and $Z_{2}$, respectively. The termination impedances of ports $1-3$ are chosen as $Z_{1}, Z_{2}$, and $Z_{2}$.

are characteristic impedances of the individual uncoupled lines in the coupled-line section, respectively. The $S$-parameters of the Marchand balun in Fig. 1 can be derived as

$$
[S]=\left[\begin{array}{lll}
S_{11} & S_{12} & S_{13} \\
S_{21} & S_{22} & S_{23} \\
S_{31} & S_{32} & S_{33}
\end{array}\right]
$$

where

$$
\begin{aligned}
& S_{11}=\frac{\left(x^{4}-y^{4}-y^{2} z^{2}\right)}{z^{2}\left(z^{2}+y^{2}\right)} \\
& S_{22}=S_{33}=\frac{\left(-x^{2} z^{2}\right)}{z^{2}\left(z^{2}+y^{2}\right)} \\
& S_{12}=S_{21}=\frac{\left(x^{3} y-x y z^{2}-x y^{3}\right)}{z^{2}\left(z^{2}+y^{2}\right)} \\
& S_{13}=S_{31}=\frac{\left(x y z^{2}+x y^{3}-x^{3} y\right)}{z^{2}\left(z^{2}+y^{2}\right)} \\
& S_{23}=S_{32}=\frac{\left(y^{4}+y^{2} z^{2}-x^{2} y^{2}\right)}{z^{2}\left(z^{2}+y^{2}\right)} .
\end{aligned}
$$

$S_{21}$ and $S_{31}$ in (2) are functions of $k$ and $\theta$ with the same magnitude and $180^{\circ}$ out of phase for all $k$ and $\theta$. To analyze the relation between bandwidth and $k$, the frequency responses for different $k$ are plotted in Fig. 2. It is observed that a higher coupling coefficient results in wider bandwidth of the Marchand balun. The flattest frequency response occurs for $k$ between $0.62-0.63$. If $k$ is smaller than 0.62 , the lowest insertion loss occurs at center frequency $f_{0}$. When $k$ is greater than 0.63 , the insertion loss at $f_{0}$ decreases. The lowest insertion loss will occur at higher and lower frequencies than $f_{0}$.

Suppose there is a desired maximum insertion loss $\left(L_{\max }\right)$, as shown in Fig. 2. If $L_{\max }$ is $4 \mathrm{~dB}$, e.g., $L_{\max }$ intersects the insertion loss with $k=0.5$ at $f_{1}$ and $f_{2}$, the insertion-loss ripple is defined as the difference between $L_{\max }$ and the lowest insertion loss at $k=0.5$ with a bandwidth of $f_{2}-f_{1}$. For a large $k$,

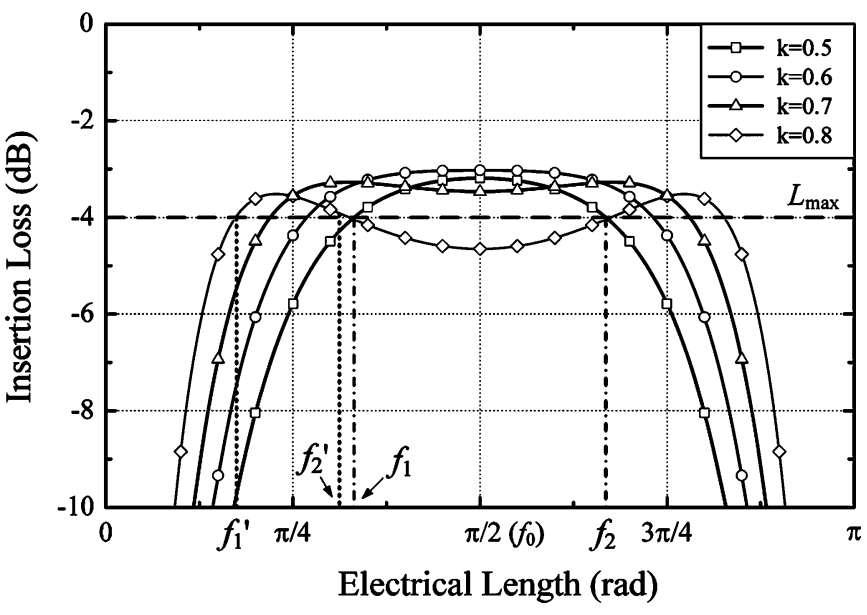

Fig. 2. $S_{21}$ and $S_{31}$ of the Marchand balun with different coupling coefficients. $L_{\max }$ denotes the maximum desired insertion loss.

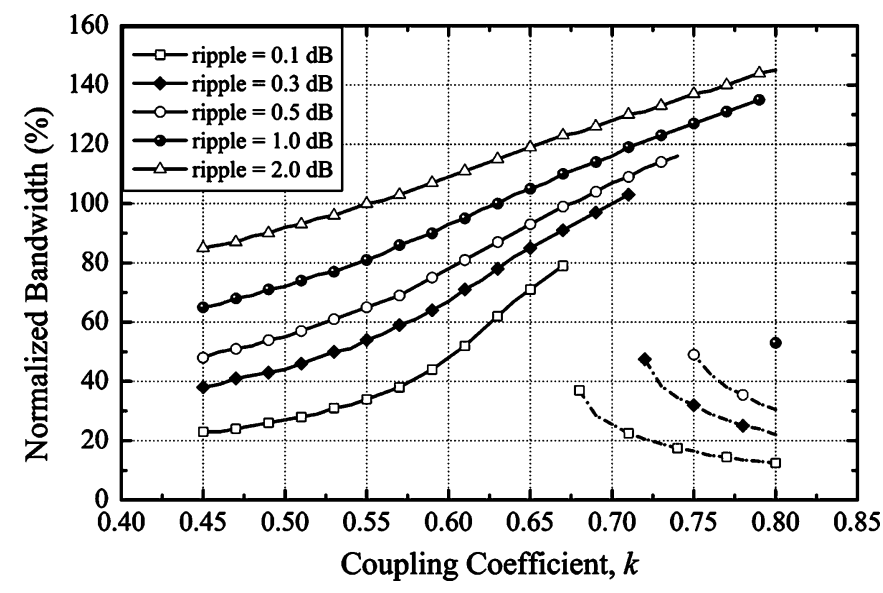

Fig. 3. Normalized bandwidth versus coupling coefficient for different insertion-loss ripple.

the insertion loss at $f_{0}$ is greater than $L_{\max }$, and $L_{\max }$ intersects the insertion loss with $k=0.8$ at $f_{1}^{\prime}$ and $f_{2}^{\prime}$, both below $f_{0}$. The insertion-loss ripple is also defined as the difference between $L_{\max }$ and the lowest insertion loss at $k=0.8$ with a bandwidth of $f_{2}^{\prime}-f_{1}^{\prime}$.

Fig. 3 shows the normalized bandwidth $\left(\left(f_{2}-f_{1}\right) / f_{0}\right)$ versus $k$ for different insertion-loss ripples. When the insertion loss at $f_{0}$ is lower than the desired $L_{\max }$, the frequencies from $f_{1}$ to $f_{2}$ can be selected. When the insertion loss at $f_{0}$ is greater than the desired $L_{\mathrm{max}}$, only the frequency range from $f_{1}^{\prime}$ to $f_{2}^{\prime}$ can be used. For certain desired $L_{\max }$, the lowest useful frequency of the Marchand balun is denoted as $f_{1}$. Fig. 4 illustrates $f_{1} / f_{0}$ versus $k$ for different insertion-loss ripples. It is observed that when $k$ increases, the Marchand balun with the same $f_{0}$ can cover lower frequencies.

\section{B. Multiconductor Coupled Lines}

The above-mentioned analysis is based on the two-conductor coupled lines with coupling coefficient $k$. The coupling coefficient between two lines increases as the mutual capacitance increases. The mutual capacitance can be increased by decreasing the spacing between the lines. However, the minimum 


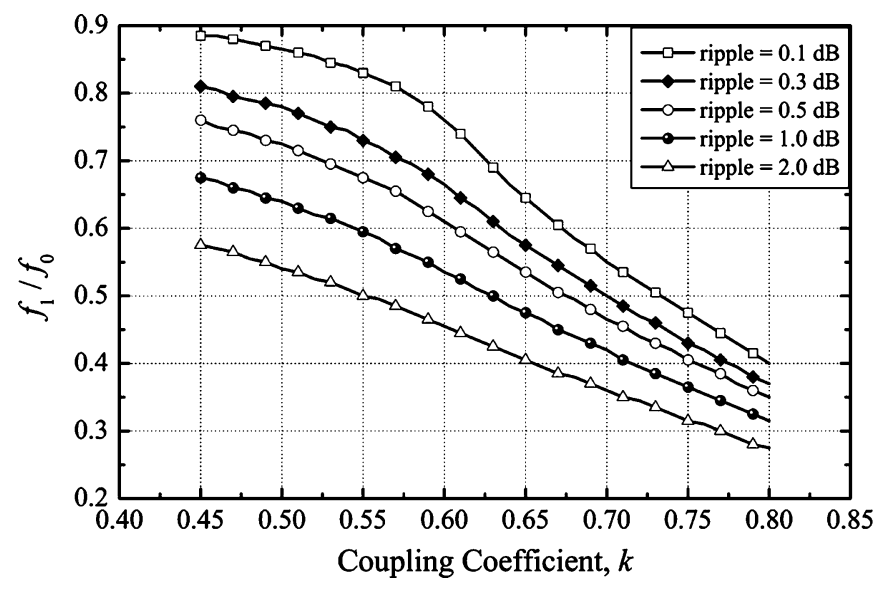

Fig. 4. $f_{1} / f_{0}$ versus coupling coefficient for different insertion-loss ripple.

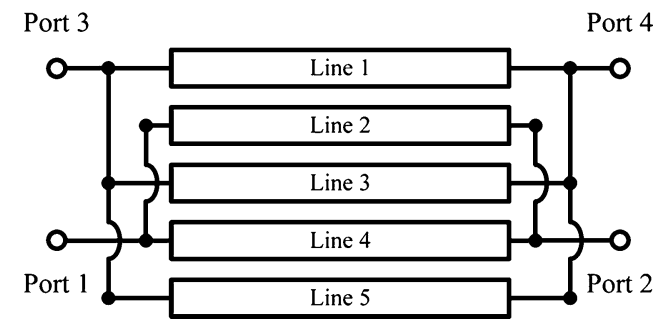

Fig. 5. Block diagram of a five-conductor coupled line.

line spacing in the implementation of the circuits limits the coupling coefficients of the planar two-conductor coupled lines. To resolve the issue in planar transmission lines, multiconductor coupled lines, e.g., Lange couplers, can be used to achieve higher coupling with the same conductor spacing [4].

Fig. 5 shows the schematic of a set of five-conductor coupled lines. Lines 1, 3, and 5 are connected together with short lines and lines 2 and 4 are connected together. The cross section of the five-conductor coupled lines is shown in Fig. 6(a), where $C_{s}$ denotes the capacitance between the conductor and ground plane, and $C_{m}$ stands for the mutual capacitance between adjacent lines. If the connections between odd-number lines (lines 1,3 , and 5) and even-number lines (lines 2 and 4) are very short compared to wavelength, the connections can be neglected, and thus, Fig. 6(a) can be simplified as Fig. 6(b). This figure can be further simplified as a pair of asymmetrical coupled lines, shown in Fig. 6(c), with equivalent capacitances $C_{s 1_{-} \text {eq }}, C_{s 2 \text { eqq }}$, and $C_{m \_ \text {eq }}$.

Another way to increase the mutual capacitances in multiconductor coupled lines is to employ broadside coupling among the coupled lines [17]. Fig. 7 shows the cross section of a set of three-conductor coupled lines with an air bridge to increase the coupling between odd and even lines. $C_{b}$ is parallel connected with the other two mutual capacitances, and thus, increases the total equivalent mutual capacitance $C_{m_{-} \text {eq }}$. The three-conductor coupled lines with an air bridge can also be simplified to a pair of equivalent two-conductor coupled lines, as shown in Fig. 6(c).

In general, even and odd modes are no longer the normal modes of the asymmetrical coupled lines [9]. The normal modes

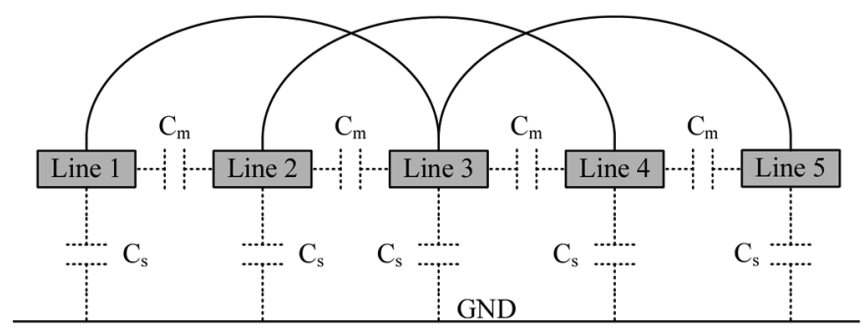

(a)

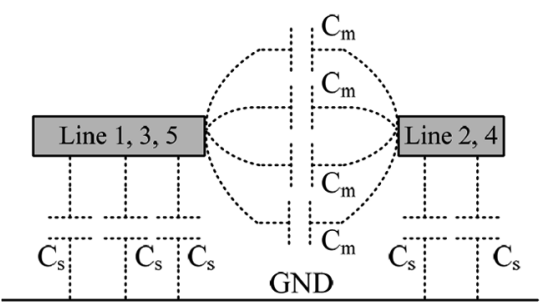

(b)

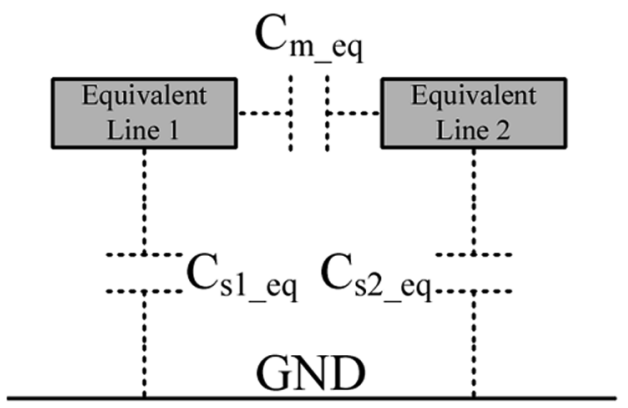

(c)

Fig. 6. (a) Cross section of the five-conductor coupled line. (b) Simplified model of the five-conductor coupled line. (c) Equivalent two-conductor coupled-line model of the five-conductor coupled line.

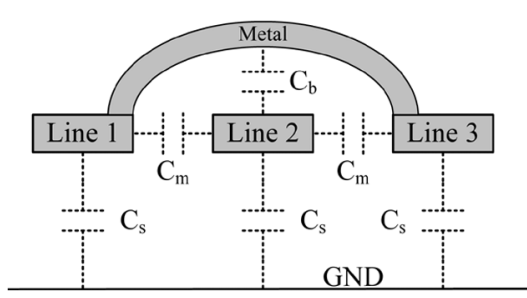

Fig. 7. Cross section of a three-conductor coupled line with air bridge to enhance coupling coefficient.

of the asymmetrical coupled lines are designated as $c$ and $\pi$ modes. For lossless TEM-mode coupled lines, the propagation constant for the $c$ and $\pi$ modes are the same. The analysis below is based on this assumption.

From [9], the coupling coefficient of Fig. 6(c) can be written as

$$
k=\frac{C_{m \_ \text {eq }}}{\sqrt{C_{1} C_{2}}}
$$

where $C_{1}=C_{s 1 \_ \text {eq }}+C_{m \_ \text {eq }}$ and $C_{2}=C_{s 2 \_ \text {eq }}+C_{m \_ \text {eq }}$. If $C_{s 1 \_ \text {eq }}$ and $C_{s 2 \_ \text {eq }}$ are fixed, $k$ increases when $C_{m \_ \text {eq }}$ increases. If $C_{m \_ \text {eq }}$ is fixed, $k$ increases when $C_{s 1 \_ \text {eq }}$ and $C_{s 2 \_ \text {eq }}$ decrease. 
The $c$ - and $\pi$-mode impedances $Z_{c}$ and $Z_{\pi}$ can be written as

$$
\begin{aligned}
& Z_{c}=\left(Z_{1} Z_{2}\right)^{1 / 2}\left[\frac{1+k}{1-k}\right]^{1 / 2} \\
& Z_{\pi}=\left(Z_{1} Z_{2}\right)^{1 / 2}\left[\frac{1-k}{1+k}\right]^{1 / 2}
\end{aligned}
$$

where $Z_{1}$ and $Z_{2}$ are the characteristic impedances of equivalent lines 1 and 2 [see Fig. 6(c)], respectively. The ratio of $Z_{c}$ and $Z_{\pi}$ is

$$
\frac{Z_{c}}{Z_{\pi}}=\left[\frac{(1+k)^{2}}{(1-k)^{2}}\right]^{1 / 2}=\frac{1+k}{1-k}
$$

The coupling coefficient $k$ increases when $Z_{c} / Z_{\pi}$ increases. Equation (6) can be also expressed as

$$
k=\frac{Z_{c}-Z_{\pi}}{Z_{c}+Z_{\pi}}
$$

The coupling coefficient of the coupled line can be determined after the $c$ - and $\pi$-mode impedances are selected.

\section{Impedance Extraction and Design Procedure}

WIN Semiconductors' standard $0.15-\mu \mathrm{m}$ high-power InGaAs/AlGaAs/GaAs pseudomorphic HEMT (pHEMT) process is used to demonstrate the design procedure. This MMIC process employs a hybrid lithographic approach using direct-write electron beam lithography for the submicrometer gate definition and optical lithography for the other steps. Other passive components including a thin-film resistor, metal-insulator-metal capacitors, spiral inductors, and air bridges are all available. There are two metal layers available in this process. The wafer is thinned to 4 mil for the gold planting of the backside, and reactive ion etching via-holes are used for dc grounding. The minimum conductor width and spacing are both $5 \mu \mathrm{m}$. The diode is realized by connecting the drain and source pads of an HEMT device to form the cathode. The cutoff frequency of the two-finger $15-\mu \mathrm{m}$ Schottky diode is approximately $381 \mathrm{GHz}$.

To examine the equal propagation constant assumption in the analysis, the seven-conductor coupled line in this 4-mil GaAs process are used to calculate the propagation constant for $c$ and $\pi$ modes. Both linewidth and line spacing are $5 \mu \mathrm{m}$. The effective dielectric constants of these two modes are calculated by the full-wave electromagnetic simulator SONNET [19]. The normalized propagation constant can be expressed as

$$
\frac{\beta_{g}}{\beta_{0}}=\frac{\lambda_{0}}{\lambda_{g}}=\sqrt{\epsilon_{r}}
$$

where $\beta_{g}$ is the propagation constant of the transmission line in the dielectric, $\beta_{0}$ is the propagation constant in free space, and $\epsilon_{r}$ is the effective dielectric constant for the transmission line. The real parts of the calculated normalized propagation constants for the two modes are shown in Fig. 8. The small difference between the propagation constants of the two modes leads to little magnitude and phase imbalance of the balun. For example, if there are

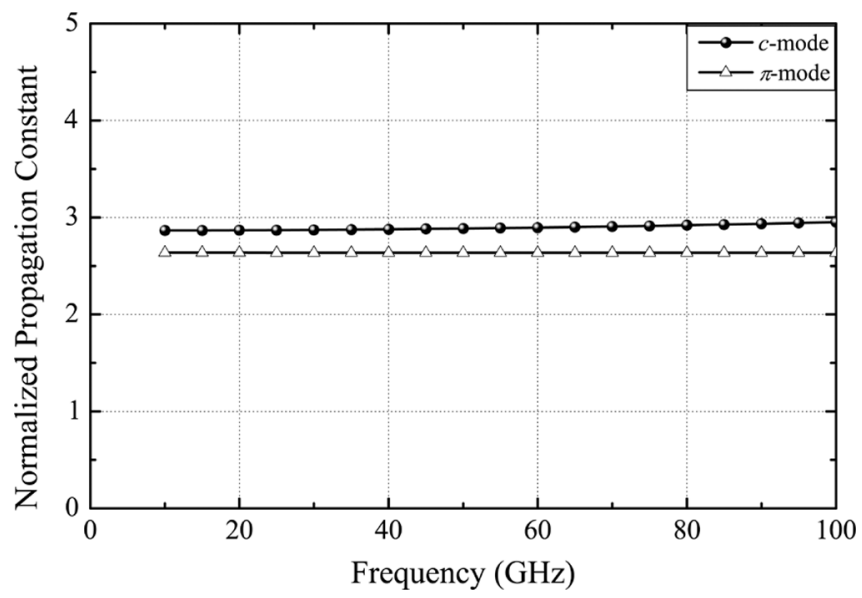

Fig. 8. Calculated normalized propagation constant $\left(\beta_{g} / \beta_{0}\right)$ for the $c$ and $\pi$ modes of the seven-conductor coupled line with linewidth and line spacing of $5 \mu \mathrm{m}$.

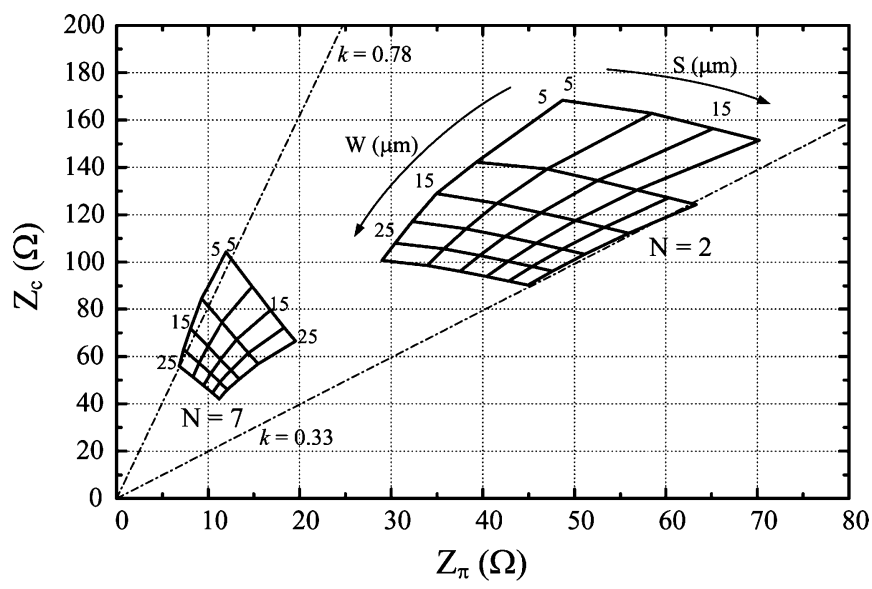

Fig. 9. Extracted $Z_{c}$ and $Z_{\pi}$ for planar coupled lines with different conductor width $(W)$ and spacing $(S)$.

two in-phase signals with equal magnitude injecting into ports 2 and 3 of an ideal balun, the signals should cancel out at port 1 , but when the balun has magnitude and phase imbalance, the signals will not completely cancel out at port 1 . The signal rejection ratio is defined as the ratio between the total in-phase input powers at ports 2 and 3 and the power at port 1 . If the magnitude and phase imbalance are less than $1 \mathrm{~dB}$ and $10^{\circ}$, the signal rejection ratio can be greater than $20.1 \mathrm{~dB}$. These values are acceptable for initial design, and thus, the assumption is valid.

In order to determine the conductor number $(N)$, conductor width $(W)$, and conductor spacing $(S)$ from the desired coupling coefficient, the relation between them can be found from (7). If $Z_{c}$ and $Z_{\pi}$ for different $N, W$, and $S$ can be found, we can use $k$ to find proper $N, W$, and $S$.

$Z_{c}$ and $Z_{\pi}$ of the multiconductor coupled lines are extracted by a full-wave electromagnetic simulator [19]. The coupled lines with $N$ from 2 to 7 are selected to extract $Z_{c}$ and $Z_{\pi}$ to form the database for $W$ and $S$ from 5 to $30 \mu \mathrm{m}$. The extracted $Z_{c}$ and $Z_{\pi}$ for different $W$ and $S$ with $N$ equal to 2 and 7 are plotted in Fig. 9. If $N$ is larger, the equiva- 


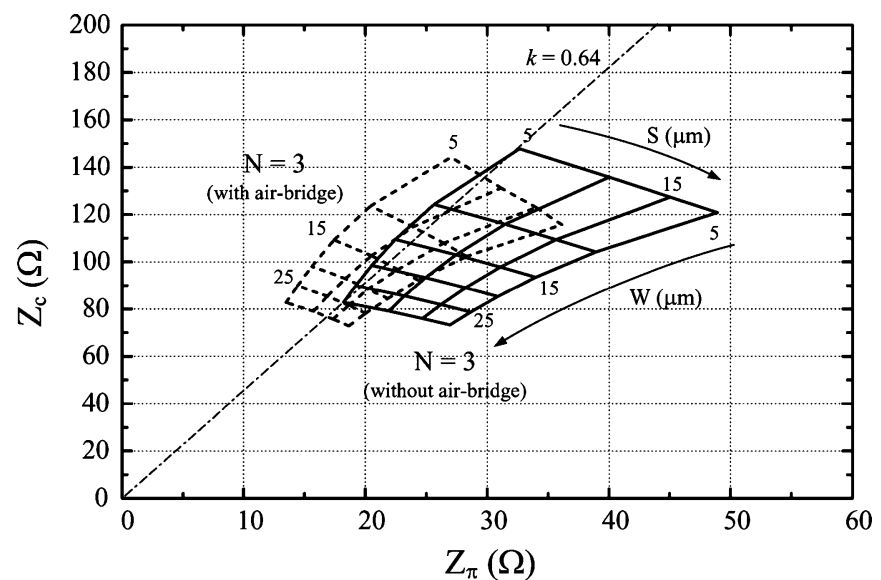

Fig. 10. Extracted $Z_{c}$ and $Z_{\pi}$ for different $W$ and $S$ with $N$ equal to 3 . The solid line is the planar three-conductor coupled lines without air bridge, and the dashed line is the three-conductor coupled lines with air bridge.

lent conductor-to-ground capacitance also becomes larger, thus decreasing the $c$-mode impedance. Although the $c$-mode impedance decreases when $N$ increases, the $\pi$-mode impedance also decreases due to the increasing of the equivalent mutual capacitance. The coupling coefficient still increases when $N$ increases.

$Z_{c}$ and $Z_{\pi}$ for the three-conductor coupled lines with and without air bridges are extracted and plotted in Fig. 10. The solid lines denote the three-conductor coupled lines without air bridges, and the dash lines are the three-conductor coupled lines with air bridges. With the air bridges, $Z_{\pi}$ decreases a lot, but $Z_{c}$ only decreases slightly, and thus, the coupling coefficient increases.

By applying (7), $k$ can be plotted in the charts of $Z_{c}$ versus $Z_{\pi}$ (Figs. 9 and 10). In Fig. 9, the curves for $k=0.33$ and $k=0.78$ are plotted, while in Fig. 10, the curve for $k=0.64$ is plotted. Most applications of the microwave baluns are balanced mixers and doublers. In these applications, the input impedance is chosen to be close to $50 \Omega$. In all integrated circuits, chip area is always an important concern. Consequently, the width, spacing, and number of conductors are chosen to be the smallest values for the desired $k$. The output impedances of the balun can be matched by properly choosing the diode size with simple matching networks.

The design procedure of multiconductor coupled-line Marchand balun is summarized as follows.

1) For a selected MMIC process, $Z_{c}$ and $Z_{\pi}$ for different $N$, $W$, and $S$ are extracted to create the database.

2) Calculate the quarter-wavelength of the desired center frequency.

3) From Figs. 3 and 4, find the proper coupling coefficient for the desired bandwidth or $f_{1} / f_{0}$.

4) Plot $k$ on the chart of $Z_{c}$ versus $Z_{\pi}$ and find $N, W$, and $S$ for the initial design.

5) Use full-wave electromagnetic simulator to verify the performance of the complete Marchand balun.

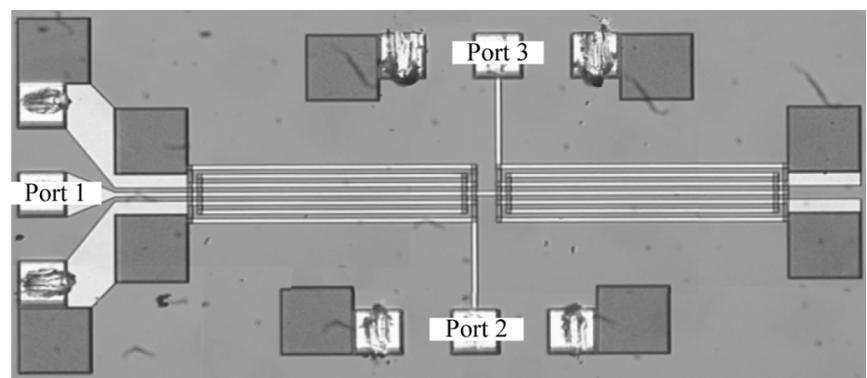

Fig. 11. Chip photograph of the seven-conductor coupled-line Marchand balun from 21 to $41 \mathrm{GHz}$ with both the conductor width and spacing of $5 \mu \mathrm{m}$.

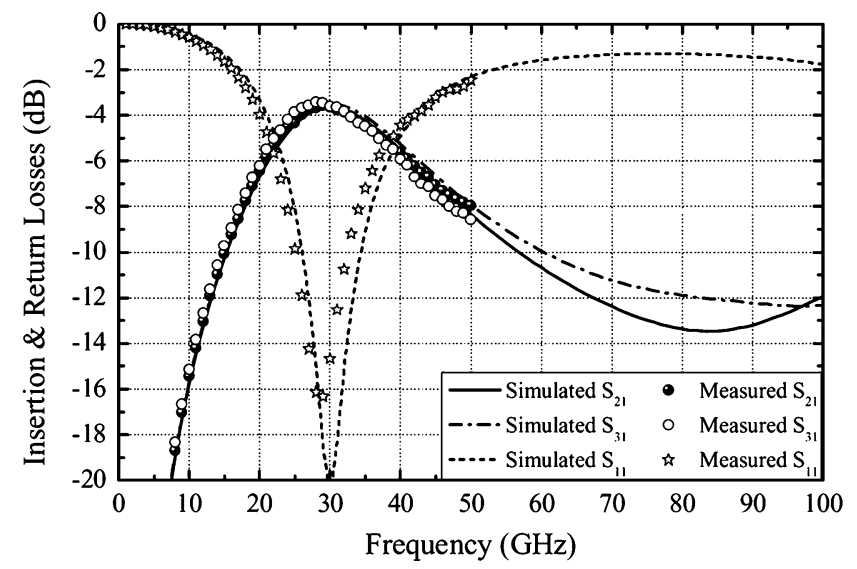

Fig. 12. Comparison of the measured and simulated insertion losses and $S_{11}$ of the seven-conductor coupled-line Marchand balun.

\section{DESIGN EXAMPLES}

One seven-conductor coupled-line Marchand balun and two MMIC balanced doublers with a multiconductor coupled-line Marchand balun using our design procedure are presented. The two doublers are both fabricated using WIN Semiconductors' standard 0.15- $\mu \mathrm{m}$ high-power InGaAs/AlGaAs/GaAs pHEMT process. The design procedure and circuit performances are described as follows.

\section{A. Seven-Conductor Coupled-Line Marchand Balun}

In this design, the desired lowest frequency is $30 \mathrm{GHz}$. In order to reduce the chip area, the $300-\mu \mathrm{m}$ coupled line, which is a quarter-wavelength line at $92 \mathrm{GHz}$, is selected to form the Marchand balun. From Fig. 4, the coupling coefficient to achieve the frequency ratio $(30 \mathrm{GHz} / 92 \mathrm{GHz})$ with the insertion-loss ripple of $1 \mathrm{~dB}$ is 0.78 . The next step is to plot for $k=0.78$ in Fig. 9 to find the proper conductor number, width, and spacing. The chosen $N$ is 7 and, $W$ and $S$ are both $5 \mu \mathrm{m}$. The balun with these parameters has $Z_{1}$ close to $50 \Omega$ in the desired frequencies and also occupies the smallest chip area with the desired $k$.

The chip photograph of the seven-conductor coupled-line Marchand balun from 21 to $41 \mathrm{GHz}$ is shown in Fig. 11. This balun is simulated using a full-wave electromagnetic simulator. The simulated and measured insertion and return losses of port 1 are shown in Fig. 12, and the simulated and measured return losses of ports 2 and 3 and phase difference are shown in Fig. 13. The insertion losses are less than $6 \mathrm{~dB}$ from 21 to 


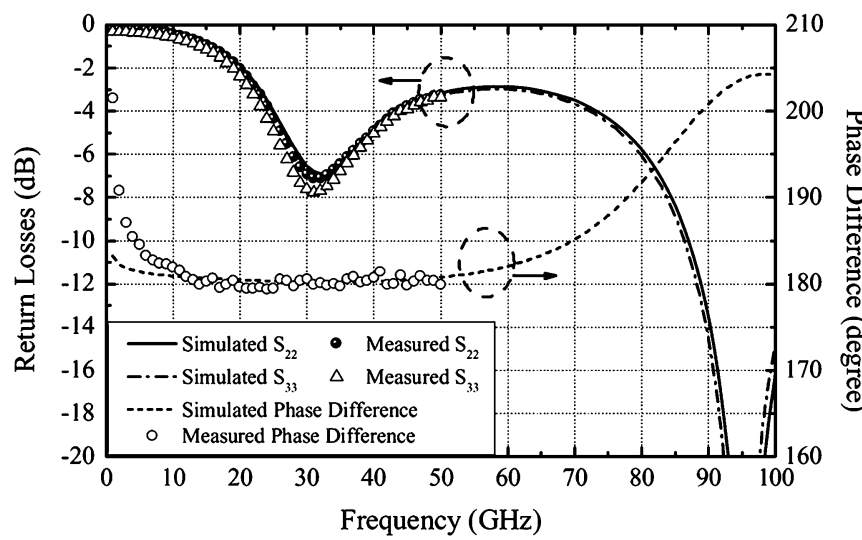

Fig. 13. Comparison of the measured and simulated phase difference $S_{22}$ and $S_{33}$ of the seven-conductor coupled-line Marchand balun.

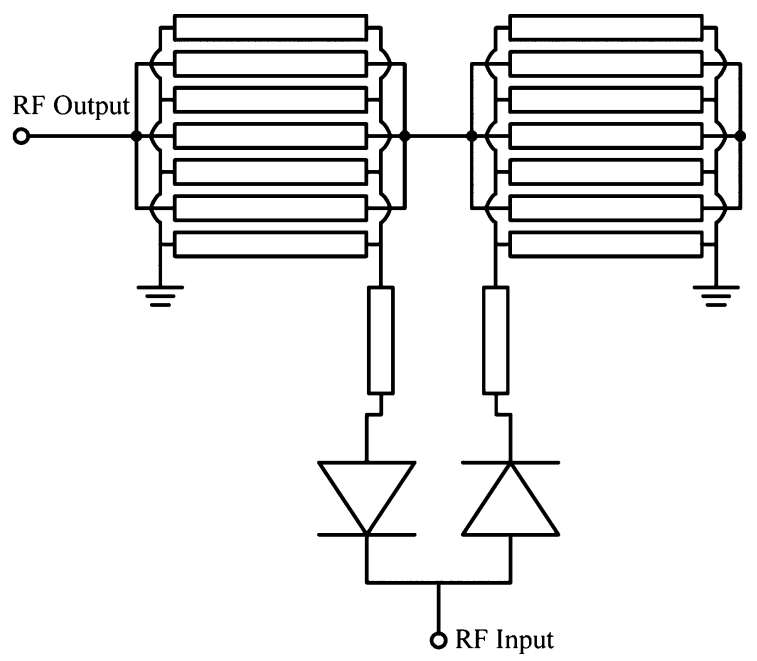

Fig. 14. Circuit schematic of the frequency doubler 1.

$41 \mathrm{GHz}$ and the return loss of port 1 is greater than $8 \mathrm{~dB}$ from 24 to $34 \mathrm{GHz}$. The magnitude and phase imbalances are within $1 \mathrm{~dB}$ and $5^{\circ}$ from 5 to $70 \mathrm{GHz}$, respectively.

\section{B. Frequency Doubler 1}

The circuit topology of this frequency doubler is shown in Fig. 14. This circuit consists of a Marchand balun and two diodes. The input power are divided into two parts to feed two antiparallel diodes. Due to the diodes being antiparallel, the generated second-harmonic signals are $180^{\circ}$ out-of-phase. The second-harmonic signals are combined through the Marchand balun at the output.

In this design, the desired output frequency range is from 30 to $50 \mathrm{GHz}$. The design procedure in Section III-C can be applied to design the Marchand balun. The chosen $N$ is 7, and $W$ and $S$ are both $5 \mu \mathrm{m}$ for the $300-\mu \mathrm{m}$ coupled lines. Using these design parameters, the Marchand balun is simulated by the full-wave electromagnetic simulator [19]. The simulated results of the Marchand balun is shown in Fig. 15. The simulated insertion losses from 30 to $50 \mathrm{GHz}$ are lower than $5 \mathrm{~dB}$. The amplitude imbalance and phase imbalance are within $1 \mathrm{~dB}$ and $10^{\circ}$, respectively.

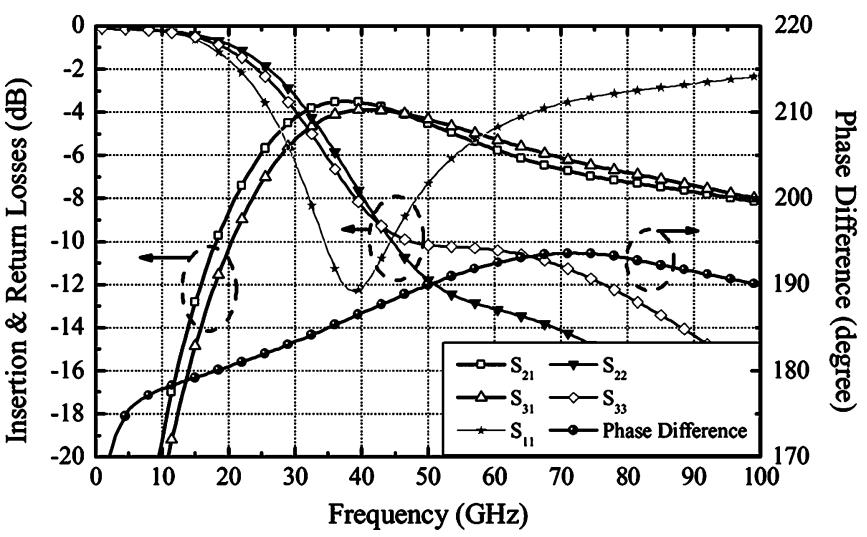

Fig. 15. Simulation results of the Marchand balun with seven-conductor coupled lines in frequency doubler 1 . The conductor width and spacing are both $5 \mu \mathrm{m}$.

TABLE I

Model Parameters of The Diode, Which Has Four FINGERS WITH TOTAL GATEWIDTH OF $30 \mu \mathrm{m}$

\begin{tabular}{cccc}
\hline \hline$I_{\mathrm{s}}(\mathrm{A})$ & $3.01 \times 10^{-14}$ & $R_{\mathrm{s}}(\Omega)$ & 13.7 \\
$N$ & 1.49 & $C_{\mathrm{j} 0}(\mathrm{~F})$ & $40.2 \times 10^{-15}$ \\
$V_{\mathrm{j}}(\mathrm{V})$ & 0.988 & $M$ & 0.5 \\
$F_{\mathrm{c}}$ & 0.6 & $B_{\mathrm{v}}(\mathrm{V})$ & 7 \\
$I_{\mathrm{bv}}(\mathrm{A})$ & $1 \times 10^{-4}$ & $N_{\mathrm{bv}}$ & 1 \\
$T_{\text {nom }}\left({ }^{\circ}\right)$ & 27 & $E_{\mathrm{g}}(\mathrm{eV})$ & 1.43 \\
\hline \hline
\end{tabular}

Next, the diode size is selected and matched to the port impedance of the Marchand balun. The diode has four gate fingers with a total finger width of $30 \mu \mathrm{m}$. The model used in circuit simulation is a general nonlinear diode model by fitting the measured direct-current current-voltage (DC-IV) curves and $S$-parameters. The model parameters of this diode are shown in Table I. In Fig. 14, two microstrip lines between diodes and the balun are used as the matching networks. These two microstrip lines can transform the output impedances of the Marchand balun conjugately matched to the diode impedance under 10-dBm driven power near the center frequency. Finally, the $S$-parameters of the balun and matching networks from SONNET results are used in the circuit simulator with diode models to simulate the entire circuit.

A chip photograph is shown in Fig. 16 with a chip size of $0.85 \mathrm{~mm} \times 0.66 \mathrm{~mm}$. This seven-conductor coupled-line Marchand balun is a planar balun without an air bridge. This circuit is measured via on-wafer probing for input and output ports through ground-signal-ground RF probes. Fig. 17 shows the comparison of simulated and measured conversion gains with a $10-\mathrm{dBm}$ input power. The conversion loss is less than $12.5 \mathrm{~dB}$ for input frequency from 11 to $25 \mathrm{GHz}$. The fundamental rejection ratio is shown in Fig. 18. The fundamental rejection ratio is greater than $19 \mathrm{~dB}$ for input frequency from 10 to $25 \mathrm{GHz}$.

\section{Frequency Doubler 2}

The circuit topology of this frequency doubler is the same with frequency doubler 1, except for the Marchand balun. The 


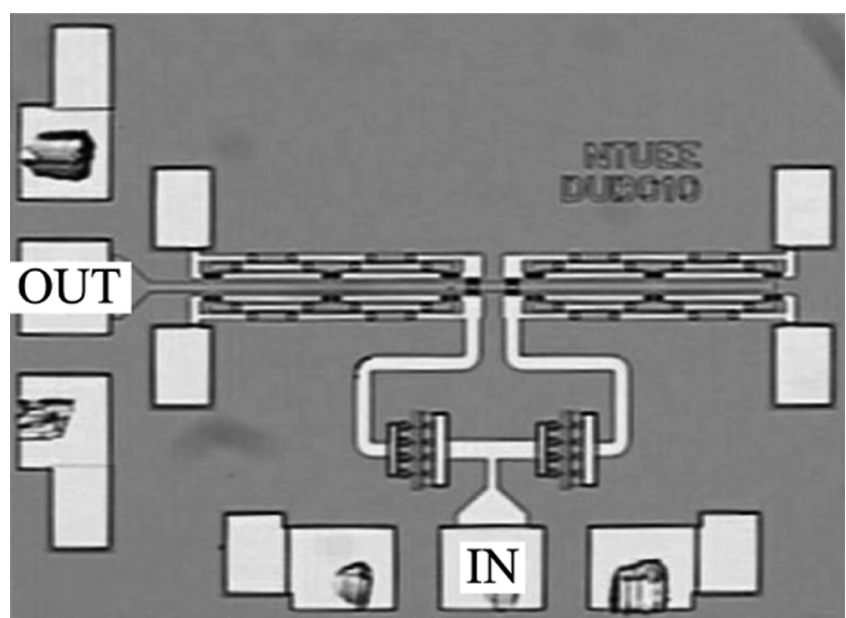

Fig. 16. Chip photograph of frequency doubler 1. The chip size of this circuit is $0.85 \mathrm{~mm} \times 0.66 \mathrm{~mm}$.

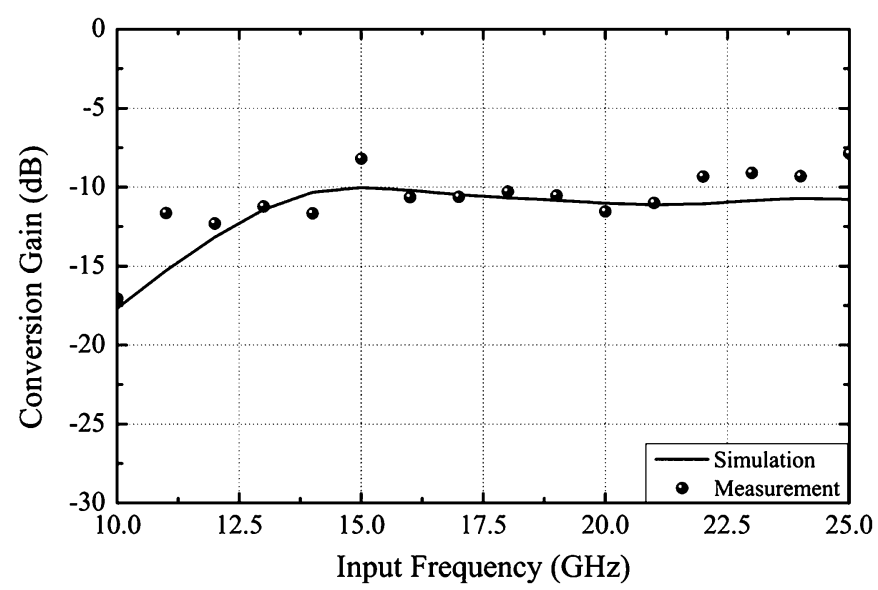

Fig. 17. Simulated and measured conversion gain of frequency doubler 1 with a $10-\mathrm{dBm}$ input power.

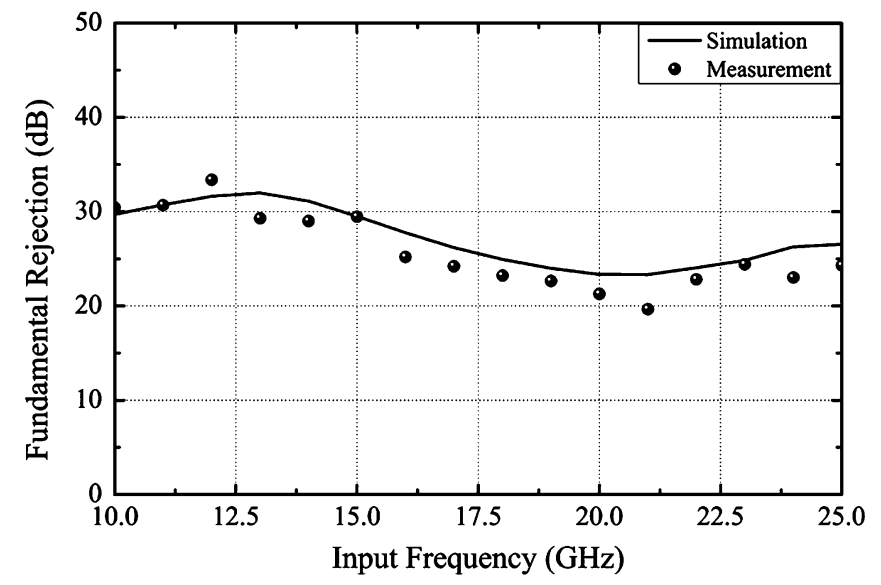

Fig. 18. Fundamental rejection ratio for frequency doubler 1.

desired output frequency range is from 80 to $120 \mathrm{GHz}$. The coupled line with length of $155 \mu \mathrm{m}$, which is $\lambda / 4$ at $166 \mathrm{GHz}$, is selected to form the Marchand balun. From Fig. 4, the coupling coefficient to achieve the frequency ratio $(80 \mathrm{GHz} / 166 \mathrm{GHz})$ with the insertion-loss ripple of $1 \mathrm{~dB}$ is 0.64 . From Fig. $10, N=3$ is

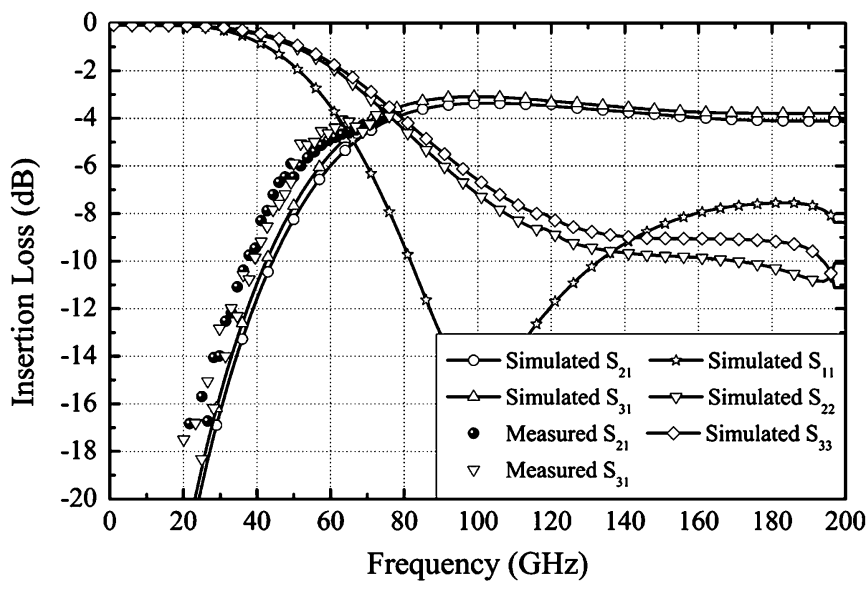

Fig. 19. Simulated and measured insertion loss of the Marchand balun with three-conductor coupled line in frequency doubler 2 . Air bridges are used to increase the coupling coefficient.

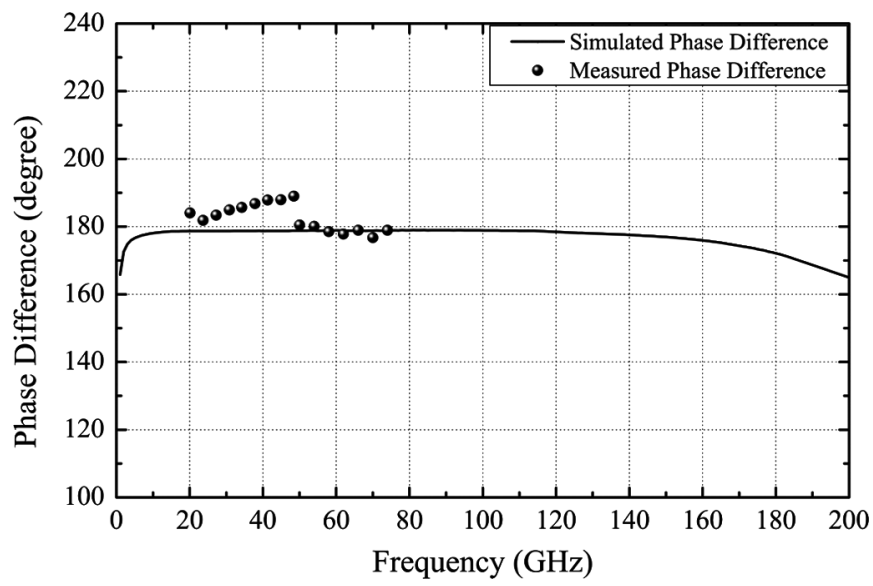

Fig. 20. Simulated and measured phase difference of the Marchand balun with three-conductor coupled line in frequency doubler 2. Air bridges are used to increase the coupling coefficient.

selected with $W$ and $S$ are both $5 \mu \mathrm{m}$. Air bridges are used to increase the coupling coefficient. In order to further increase the coupling coefficient, the center conductor is broaden to $15 \mu \mathrm{m}$ to enhance $C_{b}$ in Fig. 7 .

The simulated and measured results of the Marchand balun are shown in Figs. 19 and 20. The $S$-parameters are measured by using the port reduction methods [20]. The simulated insertion loss from 78 to $135 \mathrm{GHz}$ is lower than $4 \mathrm{~dB}$. The magnitude imbalance and phase imbalance are smaller than $1 \mathrm{~dB}$ and $10^{\circ}$, respectively.

A chip photograph is shown in Fig. 21 with a chip size of $0.56 \mathrm{~mm} \times 0.42 \mathrm{~mm}$. This circuit is also measured via on-wafer probing through ground-signal-ground RF probes. Fig. 22 shows the comparison of simulated and measured conversion gains with a $12.5-\mathrm{dBm}$ input power. The measured conversion loss is less than $12.5 \mathrm{~dB}$ for input frequency from 25 to $64 \mathrm{GHz}$. The fundamental rejection ratio is shown in Fig. 23. The measured fundamental rejection ratio is greater than $20 \mathrm{~dB}$ for input frequency from 15 to $67 \mathrm{GHz}$.

Table II shows the comparison of reported frequency doublers in the millimeter-wave region with our designs. These two frequency doublers all have the smallest chip sizes compared 


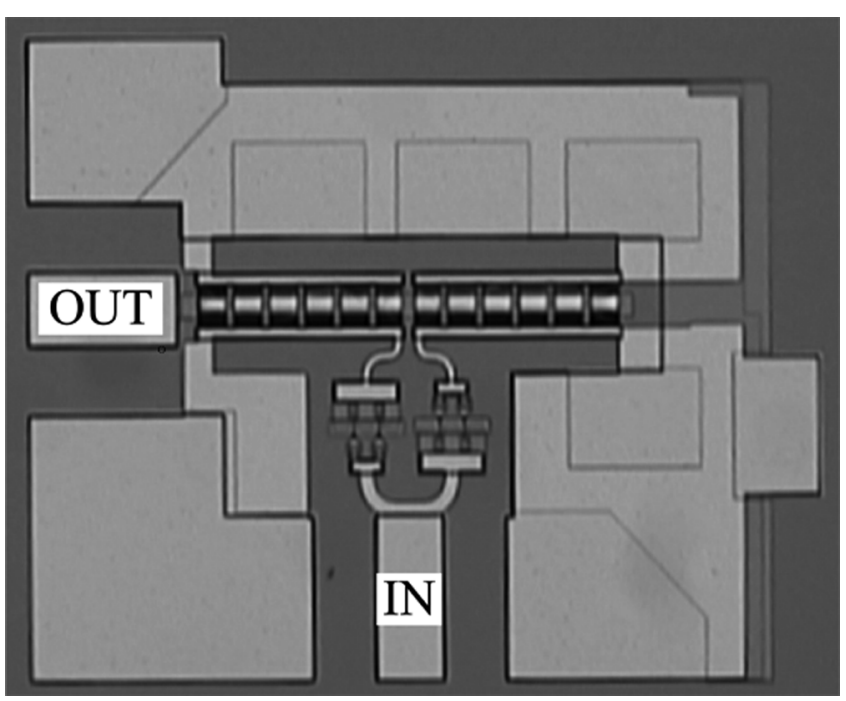

Fig. 21. Chip photograph of frequency doubler 2. The chip size of this frequency doubler is $0.56 \mathrm{~mm} \times 0.42 \mathrm{~mm}$.

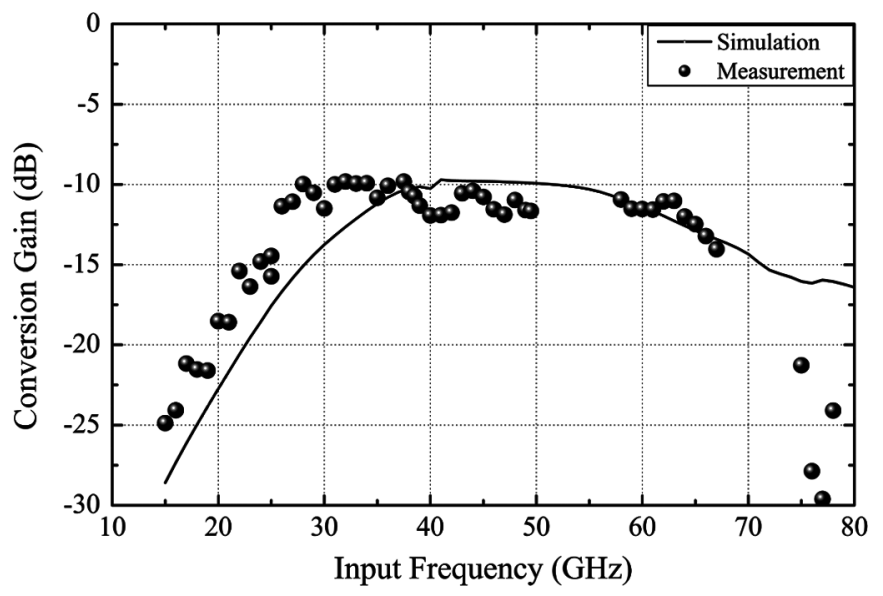

Fig. 22. Simulated and measured conversion gain of frequency doubler 2 with 12.5-dBm input power.

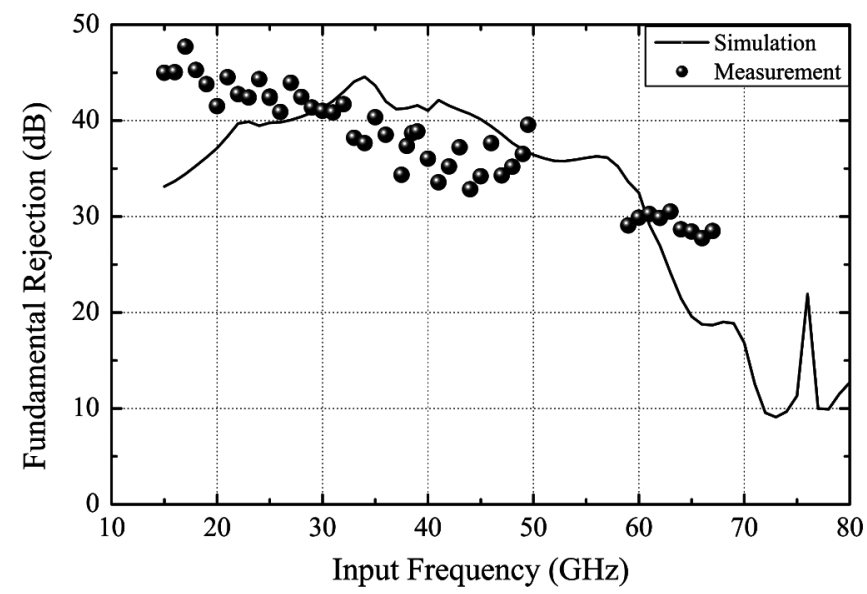

Fig. 23. Fundamental rejection ratio for frequency doubler 2.

with the MMIC doublers in the same operating frequencies. Frequency doubler 2 also achieves the widest bandwidth among the reported diode frequency doublers.
TABLE II

REPORTED PERFoRMANCE OF Wideband Millimeter-WaVe FREQUENCY DOUBLERS

\begin{tabular}{ccccc}
\hline \hline Ref. & $\begin{array}{c}\text { Bandwidth } \\
(\mathrm{GHz})\end{array}$ & $\begin{array}{c}\text { Gain } \\
(\mathrm{dB})\end{array}$ & $\begin{array}{c}\text { Fundamental } \\
\text { Rejection }(\mathrm{dB})\end{array}$ & $\begin{array}{c}\text { Chip Size } \\
\left(\mathrm{mm}^{2}\right)\end{array}$ \\
\hline \multicolumn{5}{c}{ Active Doublers } \\
\hline$[22]$ & DC-86 & -3 & - & $1.4 \times 1.6$ \\
{$[23]$} & $22-42$ & $>-10$ & $13.4-26$ & $2 \times 1$ \\
{$[24]$} & $30-50$ & -4 & $10-25$ & $1.5 \times 1$ \\
\hline \multicolumn{5}{c}{ Diode Doublers } \\
\hline$[25]$ & $70-79$ & -4 & - & $2.4 \times 1.6$ \\
{$[26]$} & $94-116$ & -13 & - & Hybrid \\
{$[27]$} & $64-78$ & -9.6 & $10-25$ & Hybrid \\
{$[28]$} & $16-40$ & -12 & 20 & $4 \times 2$ \\
This Work & $22-50$ & -12.5 & 19 & $0.85 \times 0.66$ \\
This Work & $50-128$ & -12.5 & $29-48$ & $0.56 \times 0.42$ \\
\hline \hline
\end{tabular}

\section{CONCLUSION}

A systematic analysis and design procedure for broadband multiconductor coupled-line Marchand baluns has been presented in this paper. By using this design procedure, multiconductor coupled-line Marchand baluns can be easily designed with miniature sizes. A 21-41-GHz balun and two MMIC frequency doublers have been designed and implemented to verify the design procedure. The frequency doublers achieved the smallest chip sizes with good performances among their operating frequencies.

\section{ACKNOWLEDGMENT}

The authors would like to thank C.-H. Wang, Department of Electrical Engineering and Graduate Institute of Communication Engineering, National Taiwan University, Taipei, Taiwan, R.O.C., C.-H. Tseng, Department of Electronic Engineering, National Taiwan University of Science and Technology, Taipei, Taiwan, R.O.C., and M.-F. Lei, Department of Electrical Engineering and Graduate Institute of Communication Engineering, National Taiwan University, for their helpful suggestions.

The chips were fabricated by WIN Semiconductors, Taoyuan, Taiwan, R.O.C., through the Chip Implementation Center (CIC) of Taiwan, R.O.C.

\section{REFERENCES}

[1] R. Schwindt and C. Nguyen, "Computer-aided analysis and design of a planar multilayer Marchand balun," IEEE Trans. Microw. Theory Tech., vol. 42, no. 7, pp. 1429-1434, Jul. 1994.

[2] C. Y. Ng, M. Chongcheawchamnan, and I. D. Robertson, "Analysis and design of a high-performance planar Marchand balun," in IEEE MTT-S Int. Microw. Symp. Dig., Jun. 2002, vol. 1, pp. 113-116.

[3] S. A. Maas and K. W. Chang, "A broadband, planar, doubly balanced monolithic $K a$-band diode mixer," IEEE Trans. Microw. Theory Tech., vol. 41, no. 12, pp. 2330-2335, Dec. 1993

[4] M. C. Tsai, "A new compact wideband balun," in IEEE MTT-S Int Microw. Symp. Dig., Jun. 1993, vol. 1, pp. 141-143. 
[5] P.-S. Wu, C.-H. Wang, T.-W. Huang, and H. Wang, "Compact and broadband millimeter-wave monolithic transformer balanced mixers," IEEE Trans. Microw. Theory Tech., vol. 53, no. 10, pp. 3106-3114, Oct. 2005

[6] J.-W. Lee and K. J. Webb, "Analysis and design of low-loss planar microwave baluns having three symmetric coupled lines," in IEEE MTT-S Int. Microw. Symp. Dig., Jun. 2002, vol. 1, pp. 117-120.

[7] K. S. Ang and I. D. Robertson, "Analysis and design of impedancetransforming planar Marchand baluns," IEEE Trans. Microw. Theory Tech., vol. 49, no. 2, pp. 402-406, Feb. 2001.

[8] K. Sachse, "The scattering parameters and directional coupler analysis of characteristically terminated asymmetric coupled transmission lines in an inhomogeneous medium," IEEE Trans. Microw. Theory Tech., vol. 38, no. 4, pp. 417-425, Apr. 1990.

[9] R. Mongia, I. Bahl, and P. Bhartia, $R F$ and Microwave Coupled-Line Circuits. Norwood, MA: Artech House, 1999.

[10] D. M. Pozar, Microwave Engineering, 2nd ed. New York: Wiley, 1998.

[11] C.-M. Tsai and K. C. Gupta, "A generalized model for coupled lines and its applications to two-layer planar circuits," IEEE Trans. Microw. Theory Tech., vol. 40, no. 12, pp. 2190-2199, Dec. 1992.

[12] M. Shimozawa, K. Itoh, Y. Sasaki, H. Kawano, Y. Isota, and O. Ishida, "A parallel connected Marchand balun using spiral shaped equal length coupled lines," in IEEE MTT-S Int. Microw. Symp. Dig., Jun. 1999, vol. 4, pp. 1737-1740.

[13] M. N. Tutt, H. Q. Tserng, and A. Ketterson, "A low loss, $5.5 \mathrm{GHz}-20$ GHz monolithic balun," in IEEE MTT-S Int. Microw. Symp. Dig., Jun. 1997, vol. 2, pp. 933-936.

[14] Y. C. Leong, K. S. Ang, and C. H. Lee, "A derivation of a class of 3-port baluns from symmetrical 4-port networks," in IEEE MTT-S Int. Microw. Symp. Dig., Jun. 2002, vol. 2, pp. 1165-1168.

[15] K. Nishikawa, I. Toyoda, and T. Tokumitsu, "Compact and broadband three-dimensional MMIC balun," IEEE Trans. Microw. Theory Tech., vol. 47, no. 1, pp. 96-98, Jan. 1999.

[16] J.-S. Sun and T.-L. Lee, "Design of a planar balun," in Asia-Pacific Microw. Conf. Dig., Dec. 2001, vol. 2, pp. 535-538.

[17] P.-S. Wu, C.-S. Lin, T.-W. Huang, H. Wang, Y.-C. Wang, and C.-S. $\mathrm{Wu}$, "A millimeter-wave ultra-compact broadband diode mixer using modified Marchand balun," in Gallium Arsenide and Other Semiconduct. Applicat. Symp. Dig., Oct. 2005, pp. 349-352.

[18] MatLAB. ver. 6.5, The MathWorks Inc., Natick, MA, 2002.

[19] SONNET. ver. 10.52, Sonnet Software Inc., North Syracuse, NY, 2004.

[20] H.-C. Lu and T.-H. Chu, "Port reduction methods for scattering matrix measurement of an $n$-port network," IEEE Trans. Microw. Theory Tech., vol. 48, no. 6, pp. 959-968, Jun. 2000.

[21] P.-S. Wu, C.-H. Tseng, M.-F. Lei, T.-W. Huang, H. Wang, and P. Liao, "Three-dimensional $X$-band new transformer balun configuration using the multilayer ceramic technologies," in Eur. Microw. Conf. Dig., Oct. 2004, vol. 1, pp. 385-388.

[22] V. Puyal, A. Konczykowska, P. Nouet, S. Bernard, S. Blayac, F. Jorge, M. Rjet, and J. Godin, "A DC-100 GHz frequency doubler in InP DHBT technology," in IEEE MTT-S Int. Microw. Symp. Dig., Jun. 2004, vol. 1, pp. 167-170.

[23] Y.-L. Tang, P.-Y. Chen, and H. Wang, "A broadband pHEMT MMIC distributed doubler using high-pass drain line topology," IEEE Microw. Wireless Compon. Lett., vol. 14, no. 5, pp. 201-203, May 2004.

[24] K.-L. Deng and H. Wang, "A miniature broadband pHEMT MMIC balanced distributed doubler," IEEE Trans. Microw. Theory Tech., vol. 51, no. 4, pp. 1257-1261, Apr. 2003.

[25] Y. Lee, J. R. East, and L. P. B. Katehi, "High-efficiency $W$-band GaAs monolithic frequency multipliers," IEEE Trans. Microw. Theory Tech., vol. 52, no. 2, pp. 529-535, Feb. 2004.

[26] G. P. Ermak and P. V. Kuprijanov, "Development of a planar multiplier circuit for millimeter-wave frequency multipliers," in 4th Int. Phys. Eng. Millimeter Sub-Millimeter Waves Symp., Jun. 2001, vol. 2, pp. 696-698.

[27] G.-L. Tan and G. M. Rebeiz, "High-power millimeter-wave planar doublers," in IEEE MTT-S Int. Microw. Symp. Dig., Jun. 2000, vol. 3, pp. $1601-1604$.

[28] S. A. Maas and Y. Ryu, "A broadband, planar, monolithic resistive frequency doubler," in IEEE MTT-S Int. Microw. Symp. Dig., May 1994, vol. 1, pp. 443-446.

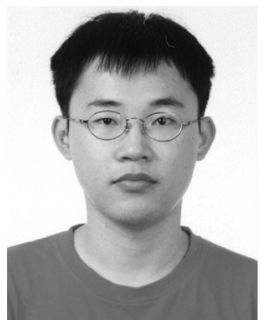

Chin-Shen Lin ( $\mathrm{S}^{\prime} 03$ ) was born in Hsinchu, Taiwan, R.O.C., in 1979. He received the B.S. degree in electrical engineering from National Taiwan University, Taipei, Taiwan, R.O.C., in 2001, and is currently working toward the Ph.D. degree at the Graduate Institute of Communication Engineering, National Taiwan University.

His research interests include monolithic microwave/millimeter-wave circuit design.

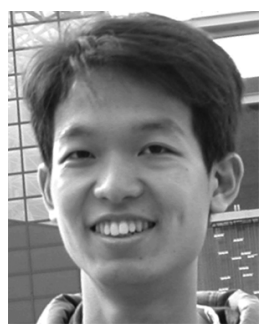

Pei-Si Wu (S'02) was born in Changhua, Taiwan, R.O.C., in 1980. He received the B.S. degree in electric engineering and Ph.D. degree from the Graduate Institute of Communication Engineering from National Taiwan University, Taipei, Taiwan, R.O.C., in 2002 and 2006, respectively.

$\mathrm{He}$ is currently a Senior Engineer with the Realtek Semiconductor Corporation, Hsinchu, Taiwan, R.O.C. His research interests include the microwave and millimeter-wave circuit designs.

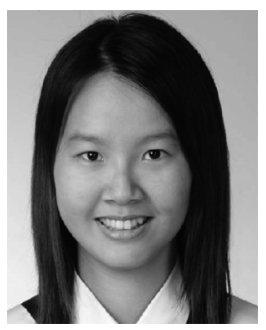

Mei-Chao Yeh was born in Kaohsiung, Taiwan, R.O.C., on January 10, 1981. She received the B.S. degree in electrical engineering from National Taiwan University, Taipei, Taiwan, R.O.C., in 2003, and the M.S. degree from the Graduate Institute of Communication Engineering, National Taiwan University Taipei, Taiwan, R.O.C., in 2005.

She is currently an engineer with the Realtek Semiconductor Corporation, Hsinchu, Taiwan, R.O.C. Her research interests are in the areas of RF and millimeter-wave integrated circuits in CMOS

technologies.

Jia-Shiang Fu (S'06) was born in Taipei, Taiwan, R.O.C., in 1981. He received the B.S. degree in electrical engineering from National Taiwan University, Taipei, Taiwan, R.O.C., in 2003, the M.S. degree in electrical engineering from The University of Michigan at Ann Arbor, in 2005, and is currently working toward the Ph.D. degree at The University of Michigan at Ann Arbor.

His research interests include reconfigurable microwave circuits and linearization of power amplifiers.

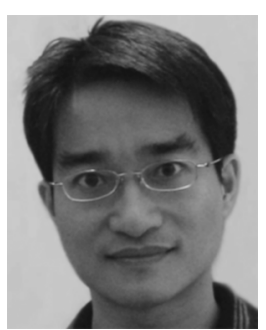

Hong-Yeh Chang (S'02-M'05) was born in Kinmen, R.O.C., in 1973. He received the B.S. and M.S. degrees in electric engineering from National Central University, Chung-Li, Taiwan, R.O.C., in 1996 and 1998, respectively, and Ph.D. degree from the Graduate Institute of Communication Engineering from National Taiwan University, Taipei, Taiwan, R.O.C., in 2004.

From 1998 to 1999, he was with Chunghwa Telecom Laboratories, Taoyuan, Taiwan, R.O.C., where he was involved in the research and development of code division multiple access (CDMA) cellular phone system. In 2004, he was a Post-Doctoral Research Fellow with the Graduate Institute of Communication Engineering, National Taiwan University, where he was involved with research on advanced millimeter-wave integrated circuits. In February 2006, he joined the faculty of the Department of Electrical Engineering, National Central University, Jhongli City, Taiwan, R.O.C., as an Assistant Professor. His research interests are microwave and millimeter-wave circuit and system designs. 


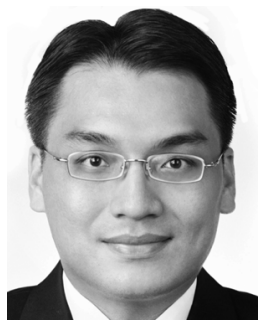

Kun-You Lin (S'00-M'04) was born in Taipei, Taiwan, R.O.C., in 1975. He received the B.S. degree in communication engineering from National Chiao Tung University, Hsinchu, Taiwan, R.O.C., in 1998, and the Ph.D. degree in communication engineering from National Taiwan University, Taipei, Taiwan, R.O.C., in 2003.

From August 2003 to March 2005, he was a Post-Doctoral Research Fellow with the Graduate Institute of Communication Engineering, National Taiwan University. From May 2005 to July 2006, he was an Advanced Engineer with the Sunplus Technology Company Ltd., Hsinchu, Taiwan, R.O.C. In July 2006, he joined the faculty of the Department of Electrical Engineering and Graduate Institute of Communication Engineering, National Taiwan University, as an Assistant Professor. His research interests include the design and analysis of microwave/RF circuits.

Dr. Lin is a member of Phi Tau Phi.

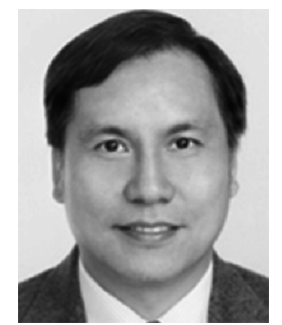

Huei Wang (S'83-M'87-SM'95-F'06) was born in Tainan, Taiwan, R.O.C., on March 9, 1958. He received the B.S. degree in electrical engineering from National Taiwan University, Taipei, Taiwan, R.O.C., in 1980, and the M.S. and Ph.D. degrees in electrical engineering from Michigan State University, East Lansing, in 1984 and 1987, respectively.

During his graduate study, he was engaged in research on theoretical and numerical analysis of electromagnetic radiation and scattering problems. $\mathrm{He}$ was also involved in the development of microwave remote detecting/sensing systems. In 1987, he joined the Electronic Systems and Technology Division, TRW Inc. He has been an MTS and Staff Engineer responsible for MMIC modeling of computer-aided design (CAD) tools, MMIC testing evaluation, and design and became the Senior Section Manager of the Millimeter-Wave (MMW) Sensor Product Section, RF Product Center. In 1993, he visited the Institute of Electronics, National Chiao-Tung University, Hsinchu, Taiwan, R.O.C., to teach MMIC related topics. In 1994, he returned to TRW Inc. In February 1998, he joined the faculty of the Department of Electrical Engineering, National Taiwan University, as a Professor. He is currently the Director of the Graduate Institute of Communication Engineering, National Taiwan University.

Dr. Wang is a member of Phi Kappa Phi and Tau Beta Pi. He was the recipient of the Distinguished Research Award of National Science Council, R.O.C. (2003-2006). In 2005, he was elected as the first Richard M. Hong Endowed Chair Professor of National Taiwan University. He has been appointed an IEEE Distinguished Microwave Lecturer for the 2007-2009 term. 